\title{
COMUNICACÃO
}

\section{Primeiro relato de Ceratocystis fimbriata causando seca em Acrocarpus fraxinifolius no Brasil}

\author{
Ana Carolina Firmino ${ }^{1 *}$, Willian Buker de Moraes $^{2}$, Edson Luiz Furtado ${ }^{2}$
}

${ }^{1}$ UNESP/Campus Experimental de Dracena, Rodovia Comandante João Ribeiro de Barros, Km 651 - Das Antas, cep: 17900-000, Dracena, SP. ${ }^{2}$ FCA/UNESP-Depto. Produção Vegetal/Defesa Fitossanitária - CEP - 18610-307 - Botucatu, SP - Brasil; *Bolsista Fapesp (Processo 2011/05710-0) Autor para correspondência: Ana Carolina Firmino (anacarfir@gmail.com)

Data de chegada: 21/11/2013. Aceito para publicação em: 26/03/2015.

$10.1590 / 0100-5405 / 1954$

O Acrocarpus fraxinifolius Wight \& Arn pertence à família Fabaceae, subfamília Caesalpinioideae, tem como sinonímia botânica Acrocarpus combretiflorus é popularmente conhecido como cedro indiano. O cedro indiano produz madeira dura, de cerne avermelhado, utilizada em construção, mobiliário e produção de celulose. Esta espécie de árvore também pode ser usada em consorcio com outras espécies cultivadas, como o café. Em 2012 plantas de cedro foram encontradas apresentando sintomas de murcha e seca na região de Avaré (SP/Brasil) (Figura 1). Estes sintomas podem ser causados por Ceratocystis spp. patógeno que vem causando problemas em culturas de importância econômica. O fungo Ceratocystis sp. coloniza o sistema vascular (xilema), causando sintomas iniciais de perda de coloração das folhagens, murcha e, conseqüentemente, morte da planta. Fragmentos do caule de cedro com sintomas foram coletados e colocados sobre isca de cenoura em câmara úmida e incubados a $25 \pm 2^{\circ} \mathrm{C}$ sob fotoperíodo alternado. Após formação de peritécio, uma porção de massa contendo ascósporos foi transferida para meio MEA (Malte, extrato de levedura e agar) para formação de colônias que foram incubadas nas condições anteriores. Dez dias após, observou-se a formação das estruturas de reprodução do fungo, que foram mensuradas utilizando-se sistema de vídeo-câmara Opton, modelo TA-0124XS, instalada em microscópio óptico. A imagem foi transmitida para computador e analisada por meio do programa EDN-2. Para a calibração do equipamento, utilizou- se uma lâmina micrografada (Carl Zeiss $\left.{ }^{\circledR}\right)$. Foram mensuradas 100 unidades de cada estrutura produzida pelo patógeno. O peritécio escuro e globoso apresentou medidas de 155,65 x 142,16 $\mu \mathrm{m}$ com rostro longo $(542,76 \mu \mathrm{m})$. Os ascósporos apresentavam formato típico de "chapéu" com as dimensões de 5,43 x 4,14 $\mu \mathrm{m}$. Foram observados clamidósporos $(12,13 \times 15,10 \mu \mathrm{m})$ e endoconídios cilíndricos $(18,03 \times 3,49 \mu \mathrm{m})$ (Figura 1). As características morfológicas indicam que o isolado do fungo obtido pertence à espécie Ceratocystis fimbriata. A região ITS1 e ITS4 do isolado sequenciada apresentou 97\% de similaridade com isolado de C. fimbriata raça C2041 (AY585345). A inoculação do isolado nas plantas foi realizada com disco de meio MEA, colonizado pelo fungo $(1 \mathrm{~cm})$, com 10 dias de crescimento. $\mathrm{O}$ disco foi introduzido em um ferimento realizado no caule ( $20 \mathrm{~cm}$ acima do solo) de mudas de cedro, com aproximadamente 7 meses de idade. Plantas também foram inoculadas somente com um disco de meio MEA, sem estar colonizado pelo fungo, como testemunha. As plantas inoculadas foram mantidas em casa-de-vegetação, com temperatura média de $27^{\circ} \mathrm{C}$. Os sintomas de murcha causados por $C$. fimbriata foram observados 30 dias após inoculação e a morte da planta 90 dias após a inoculação (Figura 1), o fungo foi obtido, novamente, do caule de cedro com sintomas em meio de cultura MEA, confirmando a patogenicidade. Assim, este é o primeiro relato de Ceratocystis fimbriata Ellis \& Halsted em cedro indiano no Brasil.

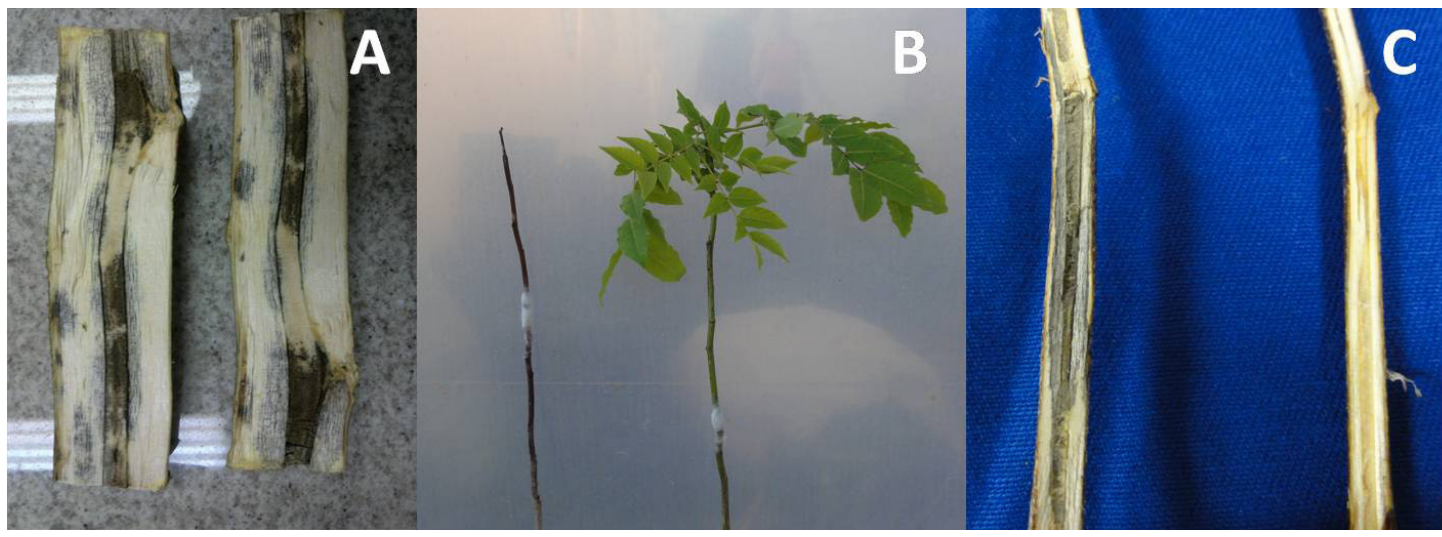

Figura 1. A. Tronco de cedro indiano retirado do campo com sintomas de Ceratocystis sp.; B. Muda de cedro indiano com seca de ponteiro (a esquerda) após a inoculação de Ceratocystis sp e planta testemunha sadia (a direita); C. Escurecimento dos vasos da plantas inoculada (a esquerda) e planta testemunha sadia (a direita). 